\title{
Article
}

\section{Estimation of Stand Structure in the Deciduous Broad-leaved Forest using Multi-temporal LiDAR Data}

\author{
Yasuteru Imai*1, Masahiro Setojima*1, Manabu Funahashi*1, Toshio Katsuki ${ }^{* 2}$ \\ and Masahiro Amano*3
}

\begin{abstract}
In this study, we tried to estimate the stand structure of deciduous broad-leaved forest and mixed forest using multi-temporal LiDAR data, and it was compared with field survey result and photo interpretation result. As a result, there is the consistency in LiDAR data obtained the same period and the reproducibility of the DSM is high. In deciduous broad-leaved forest, the amount of changes in the DSM around the defoliation allows us to understand the stand structure such as the covering situation of sub tree and shrub and floor plant. In mixed forest, the multitemporal LiDAR data is effective for the evergreen tree/deciduous tree classification.
\end{abstract}

Keywords: LiDAR, DSM, deciduous broad-leaved forest, mixed forest, stand structure

\section{INTRODUCTION}

The development of the LiDAR techniques is making progress in recent years, and many attempts have been made to estimate the ground height and the tree height, as well as to extract crowns (PERSSON et al., 2002) and estimate LAI. And there are some reports on new applications in order to understand the stand structure of the forest (SETojima et al., 2003), estimate the snow depth, and classify vegetation etc. Especially, the stand structure of the forest provides useful information that can be used for evaluation of the situation of plantation management, habitat environment of wildlife, and biodiversity.

In this study, we obtained the LiDAR data in multiple

Corresponding author: Yasuteru Imai

${ }^{* 1}$ Kokusai Kogyo Co.,Ltd. 2-24-1 Harumicho, Fuchu City, Tokyo, 183-0057, JAPAN

(yasuteru_imai, masahiro_setojima, manabu funahashi)@kkc.co.jp

${ }^{* 2}$ Forestry and Forest Products Research Institute. Matsunosato 1, Tsukuba City, Ibaraki, 305-8687, JAPAN

katsuki@ffpri.affrc.go.jp

${ }^{* 3}$ Waseda University. 2-579-15 Mikajima, Tokorozawa City, Saitama, 359-1192, JAPAN

amano@waseda.jp periods. And we calculated the difference in the DSMs (Digital Surface Model) in multiple periods (hereinafter referred to as the "difference method") to understand the stand structure of deciduous broad-leaved forest and mixed forest with different tree species and management conditions. Furthermore, the result of tree height estimation was used to classify the types of stand structures.

\section{METHOD}

Study Area

Target area was set to Tama Forest Science Garden in Tokyo, Japan. And three forests with different tree species and management conditions were selected as the verification areas (see Fig. 1).

- Area A: Well-managed cherry (Prunus yedoensis) forest

- Area B: Zelkova (Zelkova serrata) forest in natural state

- Area C: Mixed forest

\section{LiDAR Data Acquisition}

The LiDAR data used in this study are shown in Table 1. The LiDAR data collected in four periods by a fixed wing airplane were used in this study. The footprint was about 66 $\mathrm{cm}$, and the point density was 0.25 point $/ \mathrm{m}^{2}$ in all periods. 


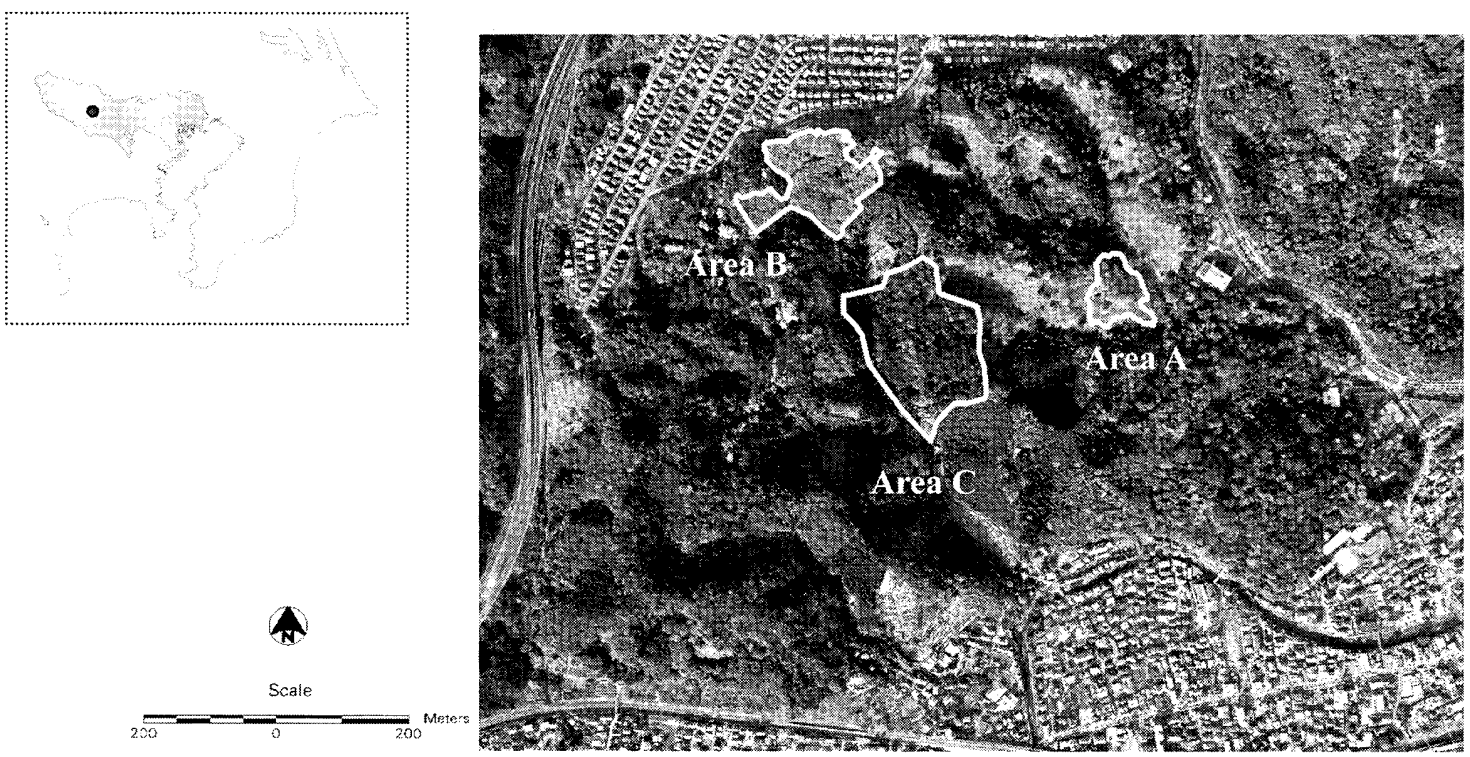

Fig. 1 Study sites of this study (Tama Forest Science Garden)

Table 1 LiDAR data used for this study

\begin{tabular}{c|c|c|c|c|c}
\hline Date & Flight Altitude $(\mathrm{m})$ & FOV (degrees) & Scan Rate $(\mathrm{Hz})$ & Swath $(\mathrm{m})$ & Density (points $\left./ \mathrm{m}^{2}\right)$ \\
\hline 2000.10 .11 & 2500 & 15 & 20 & 658 & 0.25 \\
\hline 2001.02 .12 & 2500 & 16 & 19.5 & 703 & 0.25 \\
\hline 2001.12 .03 & 2500 & 20 & 24 & 882 & 0.25 \\
\hline 2002.10 .04 & 2590 & 15 & 20 & 682 & 0.25 \\
\hline
\end{tabular}

Analysis

\section{Examination of reproducibility of DSM}

The difference method focuses on the change in the DSMs accompanying the leaf fall from autumn to winter. It is necessary to confirm that the DSMs of the same season reflect almost the same crown surface (reproducibility). We tried to compare the point clouds in the DSMs obtained two seasons before leaf fall (October 11, 2000 and October 4, 2002) to examine the reproducibility of the DSM.

The point clouds in the DSMs were prepared by extracting only the 1 st return pulses from the random points and resampling the points at $2 \mathrm{~m}$ intervals after interpolation by the TIN (triangulated irregular network).

\section{Estimation of tree height based on DSM before leaf fall and DEM after leaf fall}

We prepared the DSM grid in $2 \mathrm{~m}$ mesh before leaf fall (October 11, 2000) and the DEM (Digital Elevation Model) grid in $2 \mathrm{~m}$ mesh after leaf fall (February 12, 2001), and the DHM (Digital Height Model) was made after differentiation of the two grids.

The DHM was compared with the result of field survey, which had been obtained in Area A and a mixed forest similar to that in Area $\mathrm{C}$, to confirm the tree height estimation accuracy.

\section{Understanding the stand structure based on difference in DSMs}

We prepared the DSM grids in $2 \mathrm{~m}$ mesh collected before leaf fall (October 11, 2000), during leaf fall (December 3, 2001), and after leaf fall (February 12, 2001) to find the change in the DSM in each period after differentiation. The DSM change from October to December is called " $\triangle D_{S M_{1}}$ ", the DSM change from December to February is called " $\triangle \mathrm{DSM}_{2}$ " and the DSM change from October to February is called " $\Delta$ $\mathrm{DSM}_{3}$ ". Every $\triangle \mathrm{DSM}$ corresponds to the amount of change in the crown height in each period. After that, we tried to understand the vertical structure (stand structure) in three areas.

Approach to stand structure type classification using DHM and $\triangle D S M$

To achieve the objective classification of stand structures, we attempted to quantitative classify the types of stand structures using both $\Delta \mathrm{DSM}_{3}$ and DHM by thresholding the values. 


\section{RESULTS AND DISCUSSION}

Examination of Reproducibility of DSM

Table 2 shows the result of examination of the reproducibility of the DSM.

In Area $\mathrm{A}$, the correlation coefficient between the two DSMs with 4,025 points was 0.970 , the RMSE (Root Mean Square Error) was $1.334 \mathrm{~m}$, and the standard deviation of height difference was $1.327 \mathrm{~m}$.

In Area B, the correlation coefficient with 11,010 points was 0.959 , the RMSE was $1.546 \mathrm{~m}$, and the standard deviation of height difference was $1.493 \mathrm{~m}$.

In Area $\mathrm{C}$, the correlation coefficient with 16,936 points was 0.986 , the RMSE was $1.417 \mathrm{~m}$, and the standard deviation of height difference was $1.399 \mathrm{~m}$.

The correlation coefficient was very high in three areas, suggesting that the variation patterns of the DSMs in the two periods were similar. The RMSE and standard deviation of height difference were about $1.5 \mathrm{~m}$, which is far smaller than the range of the value of every $\triangle \mathrm{DSM}$. It is considered that the reproducibility of the DSM before leaf fall is high, representing almost the same height (crown height).
Estimation of Tree Height based on DSM before Leaf Fall and DEM after Leaf Fall

Fig. 2 shows the DHM based on the difference between the DSM before leaf fall (October 11,2000) and the DEM after leaf fall (February 12, 2001). It is assumed that Area B has many high trees of more than $20 \mathrm{~m}$ in height, Area A has comparatively low trees of $15 \mathrm{~m}$ in height, and Area $\mathrm{C}$ has high and low trees mixed together.

Table 2 shows the result of comparison between the DSM, DEM, DHM and actually measured values. It was found that the RMSE of the DSM was about 1.5-2m, the RMSE of the DEM was about $0.5 \mathrm{~m}$, and the RMSE of the DHM was about $1.5 \mathrm{~m}$. This result suggested that the DHM includes a difference about $1.5 \mathrm{~m}$ with respect to the actually measured tree height.

Understanding the Stand Structure based on Difference in DSMs

Fig. 3 shows the $\triangle$ DSMs in three periods from before leaf fall till after leaf fall. Since the DHM includes an error of about $1.5 \mathrm{~m}$ as shown in Table 2 , it was considered that the canopy condition didn't change where the $\triangle$ DSMs was less than $2 \mathrm{~m}$.

Table 2 The evaluation result on the reproducibility of the DSM and the height accuracy of the DHM

\begin{tabular}{|c|c|c|c|c|c|c|c|c|c|c|}
\hline & \multirow{2}{*}{\multicolumn{4}{|c|}{ Reproducibility of the DSM }} & \multicolumn{6}{|c|}{ Height accuracy of the DHM } \\
\hline & & & & & \multicolumn{2}{|c|}{ DSM } & \multicolumn{2}{|c|}{ DEM } & \multicolumn{2}{|c|}{ DHM } \\
\hline & $\mathrm{N}$ & C.C & RMSE & S.D & $\mathrm{N}$ & RMSE & $\mathrm{N}$ & RMSE & $\mathrm{N}$ & RMSE \\
\hline Area A & 4,025 & 0.970 & 1.334 & 1.327 & 20 & 1.434 & 526 & 0.486 & 20 & 1.489 \\
\hline Area B & 11,010 & 0.959 & 1.546 & 1.493 & - & - & - & - & - & - \\
\hline Area C & 16,936 & 0.986 & 1.417 & 1.399 & - & - & - & - & - & - \\
\hline Mixed Forest & - & - & - & - & 15 & 2.051 & 314 & 0.669 & 15 & 1.493 \\
\hline
\end{tabular}

N: Number of points, C.C: Correlation Coefficient, RMSE: Root Mean Square Error (m) S.D: Standard Deviation of height difference of two DSMs (m)

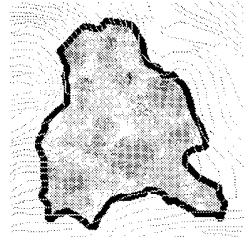

(1) Area A

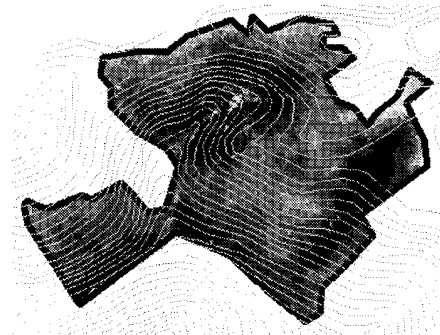

(2) Area B
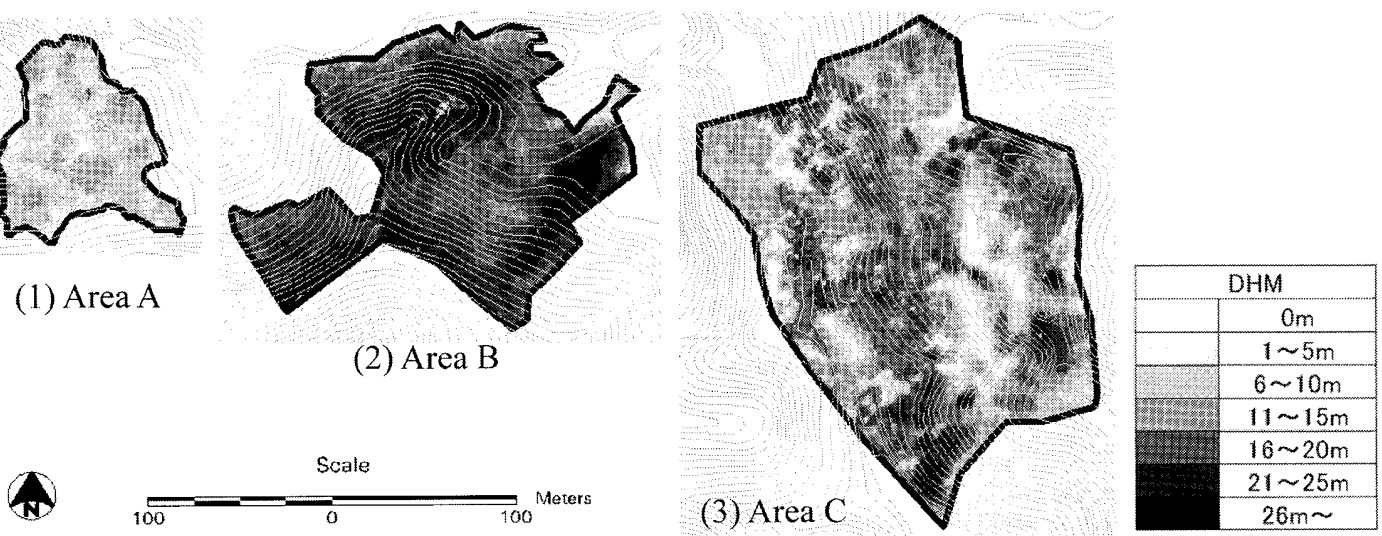

Fig. 2 The DHM of three areas 
(1) Area A
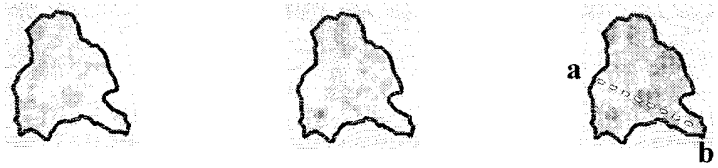

(2) Area B
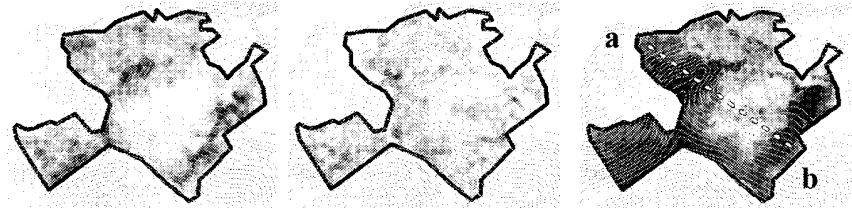

(3) Area C
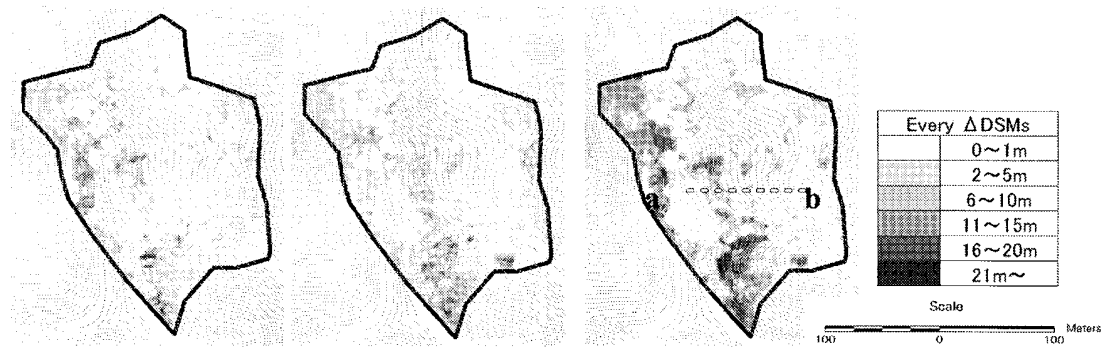

$\Delta \mathrm{DSM}_{1}($ Oct. $\sim$ Dec. $)$

$\Delta \mathrm{DSM}_{2}($ Dec. $\sim$ Feb. $)$

$\Delta \mathrm{DSM}_{3}($ Oct. $\sim$ Feb.)

Fig. $3 \Delta$ DSMs in three periods (before leaf fall till after leaf fall)

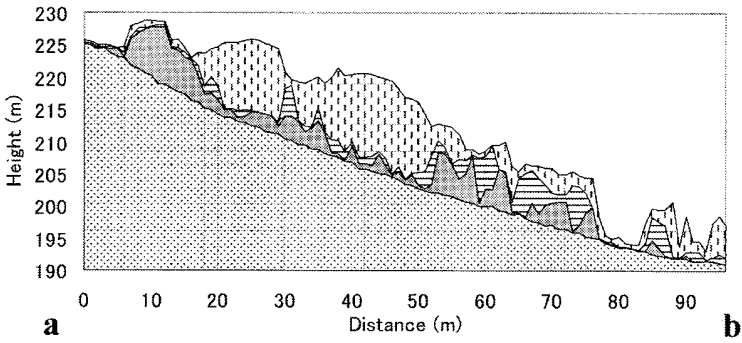

(1) Area A

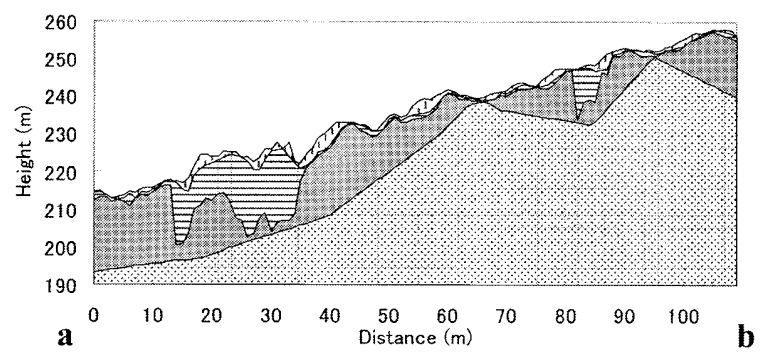

(3) Area C

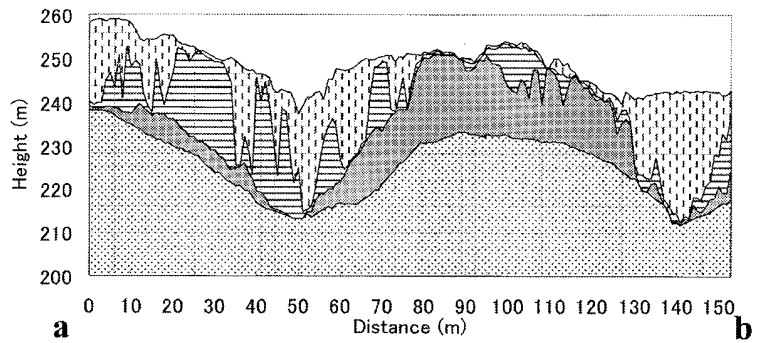

(2) Area B

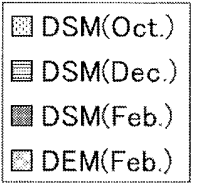

Fig. 4 Cross sectional drawing of change in DSMs during the defoliation period

In Area $\mathrm{A}$, the $\triangle \mathrm{DSM}_{1}$ was less than $10 \mathrm{~m}$ from October to December. From December to February, the $\Delta \mathrm{DSM}_{2}$ was less than $10 \mathrm{~m}$ in some places, but the number of these places was less composed to that of October to December.

In Area $\mathrm{B}$, the DSM change areas from October to December were observed in all areas except the central area, and the amount of change exceeded $20 \mathrm{~m}$ in some areas. From December to February, the DSM change areas were few compared with October to December.

In Area C, many areas were no change, but the DSM change areas were found in patches in three periods.

As a result, it is considered that the $\triangle \mathrm{DSM}_{1}$ corresponds 
to cherry trees and zelkova trees that shed leaves early.

Fig. 4 shows the cross section of the change in the DSMs from before leaf fall till after leaf fall (Refer to Fig. 3 for the cross sectional location). It visually shows the condition of low trees and forest floors in the interior of a deciduous broadleaved forest, permitting estimation of the stand structure. In forests where evergreen trees and broad-leaved trees coexist like Area $\mathrm{B}$ and Area $\mathrm{C}$, the $\triangle \mathrm{DSM}_{3}$ permits clear classification of the boundary between evergreen trees and broad-leaved trees.

Approach to Stand Structure Type Classification using DHM and $\triangle \mathrm{DSM}$

We tried to classify the stand structure types using DHM and $\triangle \mathrm{DSM}_{3}$ by thresholding the values.

Table 3 shows the concept of type classification. Based on the DHM, the dominant tree height was classified. Taking into consideration the error of the DHM, 0-1m, $1-5 \mathrm{~m}, 5-10 \mathrm{~m}$, and more than $10 \mathrm{~m}$ were regarded as the "road and herb", "shrub", "sub-high tree", and "high tree".

Based on the $\Delta \mathrm{DSM}_{3}$, the condition of the lower layer was classified. Areas where the $\Delta \mathrm{DSM}_{3}$ is $0-1 \mathrm{~m}$ were regarded as the "evergreen forest" because the seasonal change of the DSM was almost nothing, and the other areas were regarded as the "deciduous forest." In the deciduous forest, the areas where the same category of the DHM and the $\triangle \mathrm{DSM}_{3}$ were regarded as "no lower layer," the areas where the difference in the two classes were 1-5m were regarded as "herbs in lower layer," and the difference was $5-10 \mathrm{~m}$ were regarded as "shrubs in lower layer."

Fig. 5 shows the result of type classification.

Area A was mostly composed of deciduous high sub-high trees, and the lower layer had nothing or herbs only.

Area B was mostly composed of deciduous high trees, having nothing in the lower layer except the central and northern parts. The central and northern parts were composed of evergreen trees.

Area $\mathrm{C}$ was mostly composed of evergreen high/sub-high trees, and deciduous high/sub-high trees were distributed in columns and patches. In the lower layer, nothing or herbs were growing at the bottom of slopes, while herbs or shrubs were growing at the top of slopes.

To validate the result, field survey was conducted and the

Table 3 Concept of type classification of stand structure using DHM and $\Delta \mathrm{DSM}_{3}$

\begin{tabular}{|c|c|c|c|c|c|}
\hline & \multicolumn{4}{|c|}{ DHM } \\
\hline & & $0 \sim 1 \mathrm{~m}$ & $1 \sim 5 \mathrm{~m}$ & $5 \sim 10 \mathrm{~m}$ & $10 \mathrm{~m} \sim$ \\
\hline \multirow{4}{*}{$\Delta \mathrm{DSM}_{3}$} & $0 \sim 1 \mathrm{~m}$ & road and herb & $\begin{array}{l}\mathrm{U}: \text { shrub (e) } \\
\mathrm{L}: \text { indistinctness }\end{array}$ & $\begin{array}{l}\mathrm{U}: \text { sub-high tree (e) } \\
\mathrm{L} \text { : indistinctness }\end{array}$ & $\begin{array}{l}\mathrm{U}: \text { high tree (e) } \\
\mathrm{L}: \text { indistinctness }\end{array}$ \\
\hline & $1 \sim 5 \mathrm{~m}$ & - & $\begin{array}{l}\mathrm{U}: \text { shrub }(\mathrm{d}) \\
\mathrm{L}: \text { none }\end{array}$ & $\begin{array}{l}\text { U: sub-high tree (d) } \\
\mathrm{L}: \text { herbs }\end{array}$ & $\begin{array}{l}\mathrm{U}: \text { high tree }(\mathrm{d}) \\
\mathrm{L}: \text { shrubs }(\mathrm{e})\end{array}$ \\
\hline & $5 \sim 10 \mathrm{~m}$ & - & - & $\begin{array}{l}\mathrm{U} \text { : sub-high tree }(\mathrm{d}) \\
\mathrm{L}: \text { none }\end{array}$ & $\begin{array}{l}\mathrm{U}: \text { high tree (d) } \\
\mathrm{L}: \text { herbs }\end{array}$ \\
\hline & $10 \mathrm{~m} \sim$ & - & - & - & $\begin{array}{l}\mathrm{U} \text { : high tree }(\mathrm{d}) \\
\mathrm{L}: \text { none }\end{array}$ \\
\hline
\end{tabular}

U: upper layer, L: lower layer, (e): evergreen, (d): deciduous

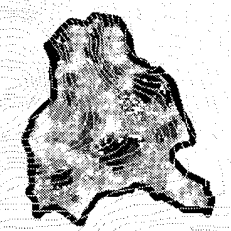

(1) Area A

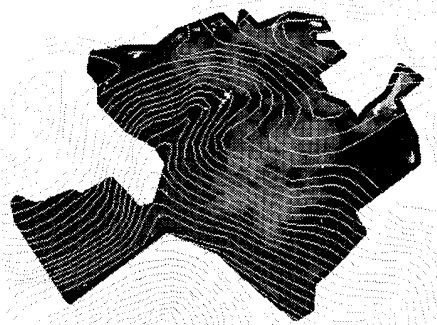

(2) Area B

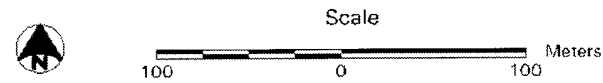

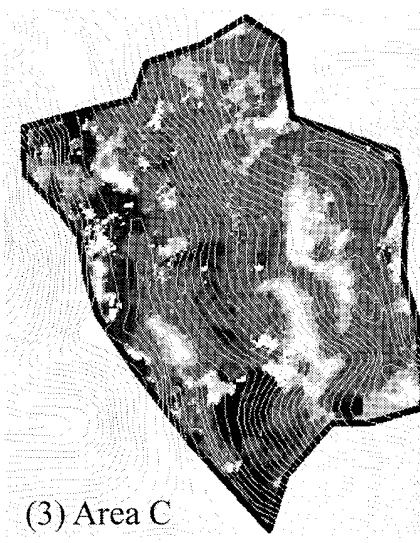

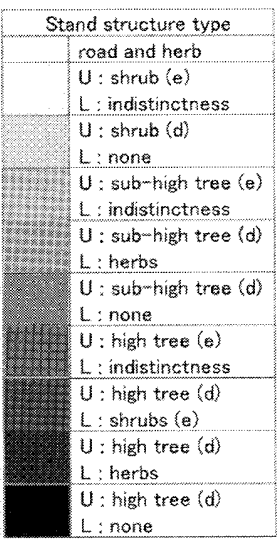

Fig. 5 The result of type classification of stand structure 
above result was compared with the cross section (see Fig. 4). As a result, the type classification was almost satisfactory, although the area with "no lower layer" was slightly larger in the classification. In mixed forest, the evergreen/deciduous classification of the high tree layer was correct, and the identification of deciduous broad-leaved trees was comparatively correct.

\section{CONCLUSION}

This study was intended to understand the stand structure of deciduous broad-leaved forest and mixed forest based on LiDAR data obtained in four periods. It is also intended to classify the types of stand structures with the help of the information about tree height.

As a result, it was found that there is consistency in the LiDAR data obtained the same period and the reproducibility of the DSM is high; the amount of changes in the DSM allows us to understand the stand structure of the interior of deciduous broad-leaved forest, as well as type classification; In mixed forest, LiDAR data collected in multiple periods are effective for classification of evergreen trees and deciduous trees.

However, the verification is insufficient at present, and it is necessary to collect the height information of high trees, shrubs, and herbs by field measurement and aerial photogrammetry to conduct quantitative verification of the results of the method described in this paper.

\section{LITERATURE CITED}

PERsson, A. et al.(2002): Detecting and measuring individual trees using an airborne laser scanner. Photogrammetric Engineering and Remote Sensing 68: 925-932

Setojima, M. et al. (2003): Basic study of tree height measurement in Satoyama Coppice Forests and identification of the distribution of deciduous broadleaf trees using airborne laser scanner data before and after defoliation. Journal of the Japanese Institute of Landscape Architecture 66(5): 503-508

(Received 15 January 2007)

(Accepted 17 Janurey 2008) 